\title{
Systems Engineering as a First Step to Effective Use of BIM
}

\author{
Henk Jan Pels, Jeroen van Beek, and Ad den Otter \\ Eindhoven University of Technology (TU/e), \\ Faculty of the Built Environment, \\ Architectural Design Management Systems \\ $\{$ h.j.pels, j.p.a.v.Beek, a.f.h.j.d.otter\}@tue.nl
}

\begin{abstract}
A Dutch AEC consulting company envisions Systems Engineering (SE) as an effective means to reduce risk in integrated AEC projects. However most of their experts doubt about the practical effectiveness. ADMS is invited to conduct a research project in order to investigate how to introduce SE in a suitable way in their practices. A research method is defined on how to assess the suitability of SE and how to enable the organization to apply it in different projects. The research shows that SE can be an effective method to reduce risk in integrated projects and helps to improves their services in this field. An instrument is developed to enable the company's consultants to apply SE effectively in Design \& Build and Design, Build and Maintain-projects.
\end{abstract}

Keywords: Systems Engineering, knowledge valorization, BIM.

\section{Introduction}

A Dutch AEC management and consultancy office, let us call it AMCO, wants to implement Systems Engineering (SE) in their processes and asks the Architectural Design Management Systems (ADMS) professional doctorate program of TU/e to help them. ADMS is a two year postgraduate technological designers program. AMCO is active in the Dutch market for utility buildings and offers it's services in all phases from initiation to demolition. Their unique selling point is Integral Project Management (IPM).With IPM, AMCO provides the customer with an (integral) housing solution, while taking over all project risks from the customer. Currently the Dutch market moves from the conventional form, where a, where a contractor is contracted after the design is finished by the architect to Design\&Build (D\&B) and Design-Build-Maintain (DBM) contract forms. In such integrated contract forms, traditional project management approaches fail to manage all risks and responsibilities related to this type of projects. Especially professional public clients tend to require SE as a method to be applied in their projects. AMCO expects SE to be a method to reduce risks in such projects and thus to be able to provide better service to their customers, to increase their margins and to maintain their competitive advantage.

For ADMS, the assignment fits in their interest in implementing Building Information Modeling (BIM). BIM can be defined as "the process of creating and 
using digital models for design, construction and/or operation of projects" [Succar, 2009]. Practice shows that implementing BIM in Dutch building industry moves forward very slowly [Iliescu, 2010]. One of the reasons is that to realise the promised benefits, BIM should be embedded in adapted processes. Implementing SE tends to help resulting in the required adaptions, so implementing SE in a AEC project is a strong step towards effective use of BIM.

\section{Research Approach}

\subsection{Research Question}

For AMCO the motive for the research was to get understanding in how SE can improve their services in integrated construction projects. In this context the research goal was to develop a project independent instrument which helps to implement SE in AMCO's services in the field of D\&B and DBM projects This resulted in the research question:

How can SE improve the services provided by $A M C O$ in $D \& B$ and $D B M$ projects in utility construction?

\subsection{Method}

The research is primarily focused on knowledge valorization rather than knowledge development. A large body of knowledge on SE exists and software tools to support the SE-processes are available on the market. Especially smaller AEC companies are uncertain about how to apply SE and whether implementation will be beneficial at all. The SE methodology has been extensively elaborated for complex high tech projects in e.g. aerospace and defense applications, but similar implementation of the full method in less complex projects seems a overkill to most of the experts in the AMCO organization. What they need is a clear view of the key elements of SE and a tool to guide them in the selection of what elements could be applied in what type of project. For the design of this tool a research approach in four steps was choosen, based on [Verschuren and Doorewaard, 2007]:

1. a) quick scan to establish current practices in AMCO,

b) determine responsibilities and commitments in D\&B / DBM projects.

2. a) acquire SE theoretical knowledge,

b) analyze differences between traditional and D\&B/DBM projects,

c) analyze practical experiences,

3. diagnose possible improvements for AMCO's services in D\&B/DBM projects,

4. design of a project supporting instrument.

From step 1 it appeared that the current practice in AMCO is to develop innovation as much as possible 'on the job', in order to remain focused on practice and to save costs. To make the tool acceptable in the organization a similar approach should be applied in the design. Therefore a combination of a 'science based' ([Dunbar, Romme en Starbuck, 2007]. [Romme en Endenburg, 2006], Van Aken, 2004]) and 
'human centered' ( [Bate and Robert, 2007], [Hatchuel, LeMasson en Weil, 2006], [Plesk, Bibby en Whitby, 2007]) approach was chosen as proposed by Pascal, Thomas and Romme, 2012. Both methods are based on the formulation of 'design principles'. Sound design is achieved by founding the design principles on organizational sciences. Practical relevance is achieved by implementing the design principles in practice according to the following steps:

- Create problem awareness,

- Develop design principles,

- Create application scenarios,

- Design and develop tangible products,

- Experiment with prototypes,

- Transformation of organization.

Data for the research was collected from literature and from several cases.

Table 1. Responsibilities and obligations according to the UAV-GC 2005 standard

\begin{tabular}{|l|l|}
\hline $\begin{array}{l}\text { Oblient } \\
\text { of information, building area and to timely making available } \\
\text { material }\end{array}$ & $\begin{array}{l}\text { Contractor } \\
\text { Obliged to realise the work according } \\
\text { to requirements stated in the contract, } \\
\text { within time and budget and with good } \\
\text { quality }\end{array}$ \\
\hline $\begin{array}{l}\text { Responsible for specifying a } \\
\text { representative, consistent and } \\
\text { unambiguous set of requirements }\end{array}$ & $\begin{array}{l}\text { Obliged to Warn when } \\
\text { inconsistencies of missing requirements } \\
\text { are detected }\end{array}$ \\
\hline $\begin{array}{l}\text { Responsible for specific predescribed } \\
\text { design or product solutions }\end{array}$ & \\
\hline
\end{tabular}

\section{Systems Engineering and D\&B/DBM projects}

\subsection{Responsibilities and Commitments}

In Dutch AEC tradition it is common to apply certain standard conditions on project specific contracts [CROW, 2005b] in order to set rights and commitments unambiguously. The UAV-GC 2005 has been developed as a standard escecially for integrated projects [CROW, 2005a] en [CROW, 2005b]. This standard has been taken as reference in step 1b. The standard assumes only two parties in the contract: the client and the contractor. The essence of responsibilities and obligations of both parties is displayed in table 1 .

\subsection{Systems Engineering Backgrounds}

The term Systems Engineering leaves room for different interpretations. According to the International Counsel on Systems Engineering (INCOSE) it is a term that can 
refer to as well a perspective, a process as a profession [INCOSE 2011]. Also the interpretation of SE can differ strongly between industry branches [Dean, Bahill en Bentz, 1997]. The USA DoD distinguishes the SE knowledge domain from SEmanagement. This indicates that the term SE has both a theoretical connotation as body of knowledge, and a practical connotation as management process. In this research we are primarily interested in the practical connotation. Based on the definitions of DoD and INCOSE we derived the following working definition as a practical starting point for the AEC industry sector:

'Systems Engineering is an interdisciplinary way of working that has been developed to design, realize and maintain, , successful housing solutions in an integral manner that probably comply to the complete set of analyzed and documented customer and user requirements.'

SE uses a specific set of instruments and processes ([DoD, 2001], [Dean, Bahill and Bentz, 1997], [Kasser, Hitchins ad Huynh, 2009], [INCOSE 2011]). Goals, deliverables and processes are also specified as an international ISO/IEC standard [ISO/IEC, 2008]. SE has extensively been applied in aerospace, defense and telecom industry.

\subsection{SE Main Characteristics}

SE has extensively been applied in aerospace, defense and telecom industry. Recently also applications in road and water construction projects have been reported [Prorail and Rijkswaterstaat, 2009]. Their experience seem to be generalizable to the utility construction area. As the name does expect, systems theory is the basis of SE [Incose, 2011]. A system can be decomposed into subsystems, that may be subsystems themselves. The other way around, a system is part of a bigger system, e.g. its environment. In this environment the system performs certain functions in order to achieve specific goals and to comply with specific requirements.

SE has three essential characteristics:

1. Requirements: the client who commissions the system specifies goals and requirements for the system,

2. Lifecycle approach: the SE processes cover the complete system lifecycle including development, operation, maintenance, refurbishment and disposal. The systems design should take the requirements of all stakeholders in all phases of the lifecycle into account. Also the relationships with supporting systems and infrastructures must be considered,

3. Verification: in each phase of its lifecycle the system should comply to all requirements and every element of the system should refer to a requirement. This consistency should be checked and approved before the start of each following lifecycle phase.

Different sources [Dean, Bahill en Bentz, 1997; Department of Defense, 2001 and INCOSE 2011] specify their own lifecycle phasings. For the purpose of this research the following phasing was chosen, mainly based on [INCOSE, 2011]: 
1. Initiating: identify stakeholders needs and requirements, explore ideas and technologies,

2. Concept: refine stakeholders needs and requirements, explore feasible concepts, propose viable solutions,

3. Development: refine system requirements, create solution descriptions, design the system, verify and validate the system,

4. Production: realise the system, inspect and verify,

5. Utilization, verify that it meets user requirements,

6. Support: keep the system operational,

7. Retirement: archive or demolish the system.

Each phase ends by passing a milestone, after verifying consistency of all deliverables. It is important to make a distinction between phases and activities/processes. Although activities like requirements analysis, design and construction are typical for certain phases, they may start before and continue after that phase: requirements may be changed during the development phase, certain construction activities may start already in the development phase, design activities may take place during support, when changes on the system are required.

The goal of the SE process is to transform the problems/needs of the client into a successful solution. This transformation process can be viewed from two different perspectives:

1. Top down decomposition from high level (system) to detailed (subsystem, component) specifications. This top down design process is mirrored in a bottom up production process. At each level of decomposition the produced/purchased component/subsystem must be verified and tested against the design specifications. This process is also known as the $\mathrm{V}$-model. In building projects the realization process seems more from lowest to highest floor, but also here there are components and subsystems delivered or assembled at the construction site, that should be verified against the design.

2. Successive transformation processes that turn the problem into a solution. The ISO/IEC 15288:2008 standard presents an overview of these processes.

A well-considered decomposition [Dean, Bahill en Bentz, 1997] brings a number of benefits. In the first place it helps to link requirements and functions to components. Thus it can be checked whether all requirements are met and all functions and components are really required. Also it supports the specification of derived requirements and functions and to keep track of their origin. Finally the decomposition is the basis for the work breakdown structure.

SE makes a distinction between technical and management processes, that support the technical processes with planning, organization and coordination [Dean, Bahill en Bentz, 1997]. The technical processes, that are specific and characteristic for SE [INCOSE, 2011] are classified in the following types:

1. Stakeholders requirements definition process: transform initial needs into a complete set of requirements for all stakeholders,

2. Requirements analysis process: transform requirements into a technical, implementation independent view of a product that could deliver the required services, 
3. Architecture design process: break down the system into subsystems and components, sufficiently detailed to verify the realized system,

4. Implementation process: realize the system components,

5. Integration process: asemble the components according to the architecture design

6. Verification process: confirm that the system is consistent with the specified design

7. Transition process: install the verified system together with relevant enabling system in the operational environment,

8. Validation process: provide objective evidence that the services provided by the system comply with the stakeholders' requirements, achieving its intended use in its intended environment,

9. Operation process: use the system in order to deliver its services,

10.Maintenance process: sustain the capability of the system to provide its services,

11.Disposal process: end the existence of the system.

The distinction between processes and lifecycle phases is important to enable proper control of concurrent engineering. In the traditional approach the naming of process types is often the same as the naming of lifecycle or project planning phases. This makes it impossible for planners or process designer to even think of planning activities of different phases concurrently. When designing new processes, like in this research for introducing SE, it is important to implement this distinction between process and phase -from the beginning- in the process design. Even when in the first implementation concurrent engineering is not applied, the distinction is needed to be able to implement it in later phases. Such implementation would be much more complex if the terminology of the process structure has to be changed again.

\subsection{Characteristics of Consultancy Services}

AMCO wants to implement SE in order to improve their services. However, their experts will only adopt SE practices if it is clear to them how SE contributes to the value of their services. AMCO provides two types of services: one is toward parties who are responsible for a housing problem, while creating housing solutions is not their core competence; the other is towards project organizations who act as contracting partner in a housing project and have no specific competence in integrated contract forms. In the first type the service is to support the client in defining their problem and taking over several risks connected to such a task. In the second type different parties have to join in one single contract in order to produce an integral answer to the contract. This requires however effective and efficient collaboration, sophisticated organization and control [Groote et al, 2001], as well as strong management of information exchange between parties [Otter and Prins, 2002]. The contracting parties are confronted with the question whether all activities needed to respond to the contract are supported by their core competences. AMCO can support them in managing the inherent risks.

Subcontracting activities brings risk, so trust is an important condition [Quinn and Hilmer, 1994]. Especially clients that do not have the technical competences to evaluate the quality of the delivered services, have a large need for insight in the process of the delivered service. Therefore strong communication, formal as well as 
informal [Otter and Prins, 2002], between contracting parties and the client is essential [Hatfield, 1993], especially when the contract stretches over several lifecycle phases and a large number of years. This communication can easily be disrupted by mechanisms like: selective perception, information overload, emotion and language differences [Robbing, Judge and Campbell, 2010].

\subsection{SE Contribution}

SE brings a uniform process structure with a strong emphasis on completeness and traceability of requirements. For the client this provides a transparent process, in which technical issues that are outside his competence, can always be traced back to requirements expressed in his own language. For the contracting parties the uniform process enables a clear and transparent assignment of responsibilities and accountabilities. The principle that released deliverables should always be proven consistent with their input requirements, enables to establish unambiguously whether the error is in the requirements or in the solution and who should have detected the inconsistency during the verification process. Thus applying SE brings extreme transparency for each party, showing his responsibilities in each specific activity and the liabilities he faces in case of errors.

\section{Diagnosis of Possible Improvements}

\subsection{Service Toward Clients in DB/DBM Projects}

Two projects have been analyzed, in order to find bottlenecks and the differences between 'traditional' (design-contract-build) projects and DB/DBM projects. For one running project participative observation techniques were applied.

The main differences detected are shown in table 2 .

Table 2. Main differences for client between traditional and DB/DBM projects

\begin{tabular}{|l|l|l|}
\hline \multicolumn{1}{|c|}{ aspect } & \multicolumn{1}{|c|}{ traditional } & \multicolumn{1}{c|}{ DB/DBM } \\
\hline Requirements (1) & $\begin{array}{l}\text { The whole set of requirements } \\
\text { evolve during the whole } \\
\text { project because of progressive } \\
\text { insight; changed requirements } \\
\text { are implemented directly in the } \\
\text { current activity }\end{array}$ & $\begin{array}{l}\text { Explicit release of complete } \\
\text { requirement early in process; } \\
\text { changes are implemented in } \\
\text { requirements document and } \\
\text { propagated to current input of } \\
\text { current activity, according to strict } \\
\text { change management }\end{array}$ \\
\hline Requirements (2) & $\begin{array}{l}\text { Requirements are mainly } \\
\text { solution/technology oriented }\end{array}$ & $\begin{array}{l}\text { Requirements can also be } \\
\text { functional?/performance oriented }\end{array}$ \\
\hline $\begin{array}{l}\text { Influence on } \\
\text { design }\end{array}$ & $\begin{array}{l}\text { The client can proactively } \\
\text { influence the design }\end{array}$ & $\begin{array}{l}\text { Only reactive influence of the client } \\
\text { through the processes of verification } \\
\text { and acceptance }\end{array}$ \\
\hline Communication & $\begin{array}{l}\text { Intensive but ill structured } \\
\text { communication with } \\
\text { contracting parties }\end{array}$ & $\begin{array}{l}\text { Well-structured communication } \\
\text { process. }\end{array}$ \\
\hline
\end{tabular}


Observation of these differences led to the following design principle in line with the chosen design method:

- Context: housing consultants who need to make requirements specification their core competence.

- Intervention: implementing an project approach based on a Systems Engineering stakeholders requirements definition process.

- Mechanism: a systems oriented project approach that helps the customer to conceptualize and define his needs.

- Output: a representative requirements specification that maximizes the chance for a successful project result.

Following this design principle an instrument was designed that can support AMCO in its aim to provide better services. The essence of this service is securing the expectations of the client in a message that is communicable to the contracting parties. In this way the chance that the client is provided with a successful solution can be increased.

\subsection{Service Toward Contracting Parties in DB/DBM Projects}

In the DB/DBM situation contracters are legaly bound to the formal requirements. In the period before this research AMCO was already involved in providing services to contracting parties in DB/DBM projects. Risks and bottlenecks in these projects were analyzed and lead to an overview of main differences between 'traditional' and DB/DBM projects as displayed in table 3.

Table 3. Main difference for contracting parties between traditional and DB/DBM projects

\begin{tabular}{|l|l|l|}
\hline \multicolumn{1}{|c|}{ aspect } & \multicolumn{1}{|c|}{ traditional } & \multicolumn{1}{|c|}{ DB/DBM } \\
\hline $\begin{array}{l}\text { Requirements } \\
\text { specification } \\
\text { status }\end{array}$ & $\begin{array}{l}\text { The requirements co-evolve } \\
\text { on basis of results of the } \\
\text { design phases. }\end{array}$ & $\begin{array}{l}\text { Results of design are legally bound } \\
\text { to the requirement specification } \\
\text { document. Each contracting party } \\
\text { must deploy is task strictly within the } \\
\text { boundaries of the requirements } \\
\text { document. }\end{array}$ \\
\hline Requirements (2) & $\begin{array}{l}\text { Building contractor is able to } \\
\text { base his price offer upon a } \\
\text { detailed design. }\end{array}$ & $\begin{array}{l}\text { Price offer is based on requirements } \\
\text { specifications? }\end{array}$ \\
\hline $\begin{array}{l}\text { Test } \\
\text { responsibility }\end{array}$ & $\begin{array}{l}\text { The client is responsible for } \\
\text { checking the quality of the } \\
\text { project result and to organize } \\
\text { acceptance activities. }\end{array}$ & $\begin{array}{l}\text { Contractors are responsible for } \\
\text { project result and should proactively } \\
\text { demonstrate that the result is } \\
\text { consistent with the client's } \\
\text { requirements. }\end{array}$ \\
\hline
\end{tabular}

The observations above led to three more design principles, as shown in table 4 . 
Table 4. Design principles for tool for contracting parties in DB/DBM projects

\begin{tabular}{|l|l|l|l|}
\hline \multicolumn{1}{|c|}{ aspect } & \multicolumn{1}{|c|}{ Design principle 2 } & \multicolumn{1}{c|}{$\begin{array}{c}\text { Design } \\
\text { principle 3 }\end{array}$} & \multicolumn{1}{c|}{ Design principle 4 } \\
\hline Context & $\begin{array}{l}\text { consultancy for } \\
\text { contracting parties }\end{array}$ & $\begin{array}{l}\text { consultancy for } \\
\text { contracting parties }\end{array}$ & $\begin{array}{l}\text { consultancy for } \\
\text { contracting parties }\end{array}$ \\
\hline Intervention & $\begin{array}{l}\text { Implement a SE based } \\
\text { requirements ananlysis } \\
\text { process }\end{array}$ & $\begin{array}{l}\text { Implement SE } \\
\text { based } \\
\text { (architectural) } \\
\text { design process }\end{array}$ & $\begin{array}{l}\text { Implement a SE based } \\
\text { verfication process }\end{array}$ \\
\hline Mechanism & $\begin{array}{l}\text { Prevent noise in } \\
\text { communication process } \\
\text { between what the client } \\
\text { wants and how the } \\
\text { contractor interprets } \\
\text { this. }\end{array}$ & $\begin{array}{l}\text { Explicit appoint } \\
\text { and manage } \\
\text { interfaces within } \\
\text { the design process } \\
\text { of the project }\end{array}$ & $\begin{array}{l}\text { Proactive testing of } \\
\text { partial solutions towards } \\
\text { the client's set of } \\
\text { requirements }\end{array}$ \\
\hline Output & $\begin{array}{l}\text { translation of customer } \\
\text { need into proper bid }\end{array}$ & $\begin{array}{l}\text { Optimal integration } \\
\text { of partial solutions }\end{array}$ & $\begin{array}{l}\text { Successful tranformation } \\
\text { of the client 's needs } \\
\text { into a satisfying solution } \\
\text { can be secured }\end{array}$ \\
\hline
\end{tabular}

Using an instrument designed according to the principles in table 4, AMCO should be able to offer services that take away risk form the contracting parties by organizing and controlling a process in which the partners can concentrate primarily on contributing their core competences while the quality of the integral result is secured according to the contractual agreement.

\section{Development of the Instrument}

The design principles as based on theory and practice show that implementing the main SE processes, can help AMCO to improve their services. Based on the practical experiences observed in various cases during the analysis, some additional design criteria have been formulated. One of these is the observation that certain software tools are useful to support the processes. The use of a web-based Requirement Specification tool stimulates a more conscious and critical formulation of requirements'. However implementation of such a tool still raises too many questions to unconditionally stimulate broad deployment. Also the large number of relationships between system elements makes the use of a software tool beneficial, to record, manage, cluster and navigate those relationships, in order to prevent overload of information. Excel spreadsheets appear not to be the best solution for this purpose. Further a software tool can stimulate to keep the project file up-to-date. Errors in the project file may have expensive consequences in the project results. Finally better structuring and visualization of basic SE processes is important to support project managers in preparing projects since simple on-the-job introduction may cause too late implementation of verification processes. 
The SE instrument, shaped as a written manual, has been developed and tested within AMCO by presenting it to five employees with experience in DB/DBM projects. They judged the instrument as complete and basically good, but still in need of more practice based examples. The content was felt to be still to theoretic. Also some improvements in readability were proposed.

\section{SE and BIM}

BIM is a method, based on a software tool, to organize the ACE process in a more effective and efficient way. Like SE, BIM is life cycle oriented. The BIM software enables to share an evolving 3D model between al project participants. This eliminates the overload of distributing paper copies as well as the need to mentally translate 2D drawings into 3D shapes, and thus should improve coordination between parties. Problem is that traditional distribution of tasks and responsibilities is based on the characteristics of paper communication, resulting in strong separation between partners and processes. The switch towards a shared design database implies the elimination of these separations and therefore causes uncertainty about roles, liabilities and distribution of costs and benefits. At the same time designers and managers have difficulty in understanding how using a BIM system will benefit them personally. Actually they believe that communicating immature information may cause expensive problems. Therefore they have the practice to delay finishing their design until their input has become stable and to publish their design not before they are sure it is complete and finished. Then they don't see the advantage of transforming this design into a part of the 3D digital model, over publishing it in $2 \mathrm{D}$ pdf format. That user requirements are strongly outdated before the design is completed, is not seen as a problem, but as a fact of life

The strong point of SE is that it shows that requirements can and must be maintained during the project and that this requires open communication between parties, especially in verification processes. When SE has been accepted in a ACE organization, then it is much easier to explain that a BIM system is much better equipped to link requirements to design choices and building components and to support verification tasks than a set of spread sheets.

Introducing SE has a much lower threshold than introducing BIM and therefore is a good first step towards BIM.

\section{Conclusion}

The main conclusion from this study is that SE is perceived by AEC management consultants as valuable for reducing risk in construction projects, especially in the case on integrated contracts with longer lifecycle scope. This is an important result, because, although SE is a quite well accepted as proven method in aerospace and high tech industry, in AEC it is still considered as a very novel approach.

The outcomes show that, although SE methodology has a mature body of knowledge, it still requires research to valorize this knowledge in a specific 
environment like AEC. The method of design principles has been proven to be very valuable in fitting new knowledge into an existing organization. In other words, it has been shown that knowing how to valorize knowledge, is a relevant piece of knowledge itself.

As a final remark it can be noted that the introduction of SE in an AEC process can be a valuable first step on the way to effective use of BIM. SE requires software support to manage the process of requirements specification, in order to keep the increasing number of requirements conceivable for the customer as well as for the contractors. Further software support is needed to manage the complexity of relationships between requirements, functions and components, in order to keep requirements traceable. In this research project it was demonstrated that good management of communication is needed. A Building Information Model is supposed to be the ultimate means of communication in a AEC project. This means that after SE has been accepted as a standard practice in daily work, it is much easier to explain the value of BIM.

\section{References}

[Aken, van, 2004] Van Aken, J.E.: Management research on the basis of the design paradigm: the quest for field-tested and grounded technological rules. Journal of Management Studies, 219-246 (2004)

[Bate and Robert, 2007] Bate, P., Robert, G.: Toward more user-centric OD: lessons from the field of experience-based design and a case study. Journal of Applied Behavioral Science, 41-66 (2007)

[CROW, 2005a] CROW, UAV-GC 2005. Model Basisovereenkomst en toelichting. Ede, CROW (2005a)

[CROW, 2005b] CROW, Toelichting bij Model Basisovereenkomst en UAV-GC 2005. Ede, CROW (2005b)

[Dean, Bahill en Bentz, 1997] Dean, F.F., Bahill, A.T., Bentz, B.: A Road Map for Implementing Systems Engineering. Albuquerque, Sandia National Laboratories (1997)

[Dunbar, Romme en Starbuck, 2007] Dunbar, R., Romme, A., Starbuck, W.: Creating better understandings of organizations while building better organizations. In: Handbook of New Approaches to Organization Studies, pp. 554-571. Sage, Los Angeles (2007)

[Hatchuel, Lemansson en Weil, 2006] Hatchuel, A., Lemasson, P., Weil, B.: Building innovation capabilities: the development of desing-oriented organizations. In: Innovation Science and Institutional Change: A Research Handbook, pp. 294-312. Oxford University Press, Oxford (2006)

[Iliescu, 2010] Iliescu, I.A.: Let's BIM, Final ICA report, Eindhoven University of Technology, Advanced Design Management System (2010)

[INCOSE 2011] INCOSE, Systems Engineering Handbook. A guide for system life cycle processes and activities. International Counsel on Systems Engineering, San Diego (2011)

[ISO/IEC, 2008] ISO/IEC, ISO/IEC 15288:2008(E). Systems and software engineering System life cycle processes. Geneva, ISO (2008)

[Kasser, Hitchins en Huynh,2009] Kasser, J., Hitchins, D., Huynh, T.V.: Reengineering Systems Engineering. In: Proceedings of the 3rd Asia-Pacific Conference on Systems Engineering (APCOSE), Singapore (2009) 
[Mintzberg, 1983] Mintzberg, H.: Structures in fives: designing effective organizations. Prentice-Hall, New Jersey (1983)

[Otter and Prins, 2002] den Otter, A.F., Prins, M.: Architectuaral design management within the digital design team. Engineering, Construction and Architectural Management (ECAM) Article, 162-173 (2002)

[Plesk, Bibby en Whitby, 2007] Plesk, P., Bibby, J., Whitby, E.: Practiacal methods for extracting explicit design rules grounded in the experience of organizational managers. Journal of Applied Behavioural Science, 153-170 (2007)

[Prorail en Rijkswaterstaat, 2009] Prorail en Rijkswaterstaat, Leidraad voor Systems Engineering binnen de GWWSector. Prorail en Rijkswaterstaat (2009)

Romme, A.G.L.: Making a difference: organization as design. Organization Science, 558-573 (2003)

Romme, A.G.L., Endenburg, G.: Construction Principles and Design Rules in the Case of Circular Design. Organization Science 17(2), 287-297 (2006)

[Succar, 2009] Succar, B.: Building Information Modelling Maturity Matrix. In: Underwood, J., Isikdag, U. (eds.) Handbook of Research on Building Information Modeling and Construction Informatics: Concept and Technologies, pp. 65-103. Information Science Publishing (2009)

[Verschuren and Doorewaard, 2007] Verschuren, P.J.M., Doorewaard, J.A.C.M.: Het ontwerpen van een onderzoek. Den Haag, Boom Lemma Uitgevers (2007) 